References:

1) Battaglia FC, Meschia G (in press), An introduction to fetal physiology, Academic Press, New York

2) Bel1 AW, Battaglia FC, Makowski EL and Meschia G (1985) Relationship between metabolic rate and body size in fetal life. Biol Neonat 47, 120-123

3) Bell AW, Kennaugh JM, Battaglia FC, Makowski EL and Meschia G (1986) Metabolic and circulatory studies of the fetal lamb at mid gestation. Amer $J$ Physiol (in press)

4) Kennaugh JM, Bell AW, Battaglia FC and Meschia G (in preparation) Ontogenetic changes in leucine disposal rate, oxidation rate and protein synthetic rate during fetal life.

\section{FETAL HEPATIC BLOOD FLOW AND METABOLISM}

Abraham M. Rudolph

Department of Pediatrics and Cardiovascular Research Institute, University of California, San Francisco, U.S.A.

During fetal life, the liver receives highly oxygenated blood and carbohydrate substrates from the mother across the placenta, via the umbilical veins. The importance of the liver in determining oxygen and sub strate delivery to the fetal body has been studied in chronically-instrumented fetal lambs in utero both under normal and acute stress situations. Hepatic blood flow was measured by the radionuclide-labelled microsphere method and hepatic oxygen consumption and carbohydrate substrate uptake or release was calculated using the Fick Principle. Normally, somewhat less than half the umbilical venous blood enters the hepatic circulation; the remainder passes through the ductus venosus directly to the inferior vena cava. Almost all portal venous blood is distributed to the right liver lobe. During fetal hypoxemia, and particularly with reduced umbilical venous return due to cord compression, the proportion of umbilical venous blood entering the liver is greatly reduced. The livex is metabolically very active and accounts for 20-25\% of total fetal $\mathrm{VO}_{2}$. Hepatic oxygen consumption, particularly of the right lobe, is however reduced during hypoxemia, linearly in relation to oxygen delivery. Normally, glucose is delivered from the placenta, and there is little glucose uptake or release by the liver, but during hypoxemia a considerable proportion of total glucose supply is derived from the liver. Lactate is delivered to the fetal body from the placenta; the liver receives about 1 mol. $\min ^{-1} .100 \mathrm{~g}^{-1}$ and, although it extracts only about 78 of lactate, this accounts for almost 908 of the net fetal lactate uptake.

Although some controversy exists, it is generally agreed little gluconeogenesis occurs in the fetus. However, gluconeogenesis is initiated soon after bixth. Possible mechanisms that could initiate hepatic gluconeogenesis after birth have been examined by simulating perinatal events. Hepatic gluconeogenesis was studied by infusing ${ }^{14 C_{-}}$-labelled lactate or alanine and determining the amount of $14 \mathrm{C}_{-}$glucose produced by the liver under steady state conditions. Normally, minimal - if any - gluconeogenesis by the liver can be demonstrated in the fetal lamb. Ventilating the lamb in utero increased arterial oxygen saturation to levels achieved after birth, but did not induce gluconeogenesis. Also gluconeogenesis could not be stimulated by prenatal administration of cortisol for 48 hours, or, in preliminary studies, by thyreoid hormone infusion. Acute compression of the umbilical cord produced a marked fall in hepatic blood flow and oxygen and substrate delivery, but did not stimulate gluconeogenesis. Thus other mechanisms must be responsible for initiation of gluconeogenesis after birth; these are being explored.

PHARMACOGENETICS: ITS RELEVANCE TO INDIVIDUALIZED DRUG THERAPY

Stephen P. Spielberg

Division of Clinical Pharmacology, Hospital for Sick Children, Toronto, Ontario, Canada.

Inherited differences in the handling of and response to drugs, interacting with variables such as age, sex and "environmental" exposures, have a major impact on the wide inter-individual variation in drug efficacy, kinetics and toxicity seen in the human population. Developments in analytical methods and cellular and molecular biology have revealed a wide range of polymorphisms in drug metabolizing enzymes. The gene frequencies for such polymorphisms are not uniformly distributed through the population (1). Thus, while $<58$ of the Caucasian population are unable to hydroxylate mephenytoin, this abnormality (inherited as an autosomal recessive trait) is present in nearly $25 \%$ of Japanese (2). Use of dosing recommendations based on small numbers of Caucasian subjects would be expected to produce blood-level related toxicity in a sizeable portion of Japanese patients. Polymorphic oxidation of debrisoquine has been noted in many ethnic groups. In most populations, inability to metabolize debrisoquine is associated with inability to oxidize sparteine. In Ghana, however, a different allele appears to exist and while the former compound is not recognized by the specific cytochrome P-450, the latter is handled normally (3). Such heterogeneous polymorphisms emphasize the need to individualize therapy, and the difficulty in extrapolating data from one population group to another.

Recently we have found that susceptibility to idiosyncratic "hypersensitivity" reactions to aromatic anticonvulsants results from a heterogeneous group of inherited abnormalities in the ability to detoxify reactive metabolites of the drugs $(4,5)$. The same abnormality in detoxifying metabolites of phenytoin predisposes fetuses exposed to the drug in utero to major birth defects such as congenital heart disease, cleft palate, and microcephaly (6). In the adult, we believe that a major defect (possibly homozygosity for an abnormal epoxide hydrolase) is necessary to alter the balance between production and detoxification of metabolites to result in overt toxicity. In the fetus, the heterozygous state appears sufficient to increase the likelihood of major birth defects. This is an example of interaction between genetically determined predisposition to toxicity and agedependent development of critical enzyme pathways. Furthermore, minor stigmata of the "fetal hydantoin syndrome" were not associated with defective arene oxide metabolite detoxification. Complex interactions of genetics, pharmacogenetics, and environmental variables ultimately may determine the outcome of in utero exposure to drugs.

References:

1) Kalow W, Goedde HW, Agarwal DP (eds) 1985, Ethnic differences in reactions to drugs and xenobiotics, Alan $\mathrm{R}$ Liss Inc., New York

2) Jurima $M$ et al 1985, Brit J Clin Pharmacol 19, 483

3) Woolhouse NM et al 1984, Clin Pharmacol Ther 36,374

4) Spielberg SP et al 1981, N Engl J Med 305, 722

5) Spielberg SP 1984, Fed Proc 43, 2308

6) Stricker SM et al 1985 Lancet II, 746 